\title{
氢能利用安全技术研究与标准体系建设思考
}

\author{
曹湘洪，魏志强 \\ （中国石油化工集团有限公司，北京 100728）
}

摘要: 中国车用氢能产业正处于快速起步阶段。充分认识氢气的危险性、安全利用氢能是我国车用氢能产业健康发展的基础。 本文在分析氢气的物理化学性质和氢气与材料相容性问题后, 提出了实现氢气安全利用的三个基本原则; 系统介绍了日本在 高压氢能安全利用方面的研究成果与安全技术措施, 提出了我国燃料电池汽车 (FCEV) 发展中安全利用氢能的建议: 一是 总体规划设计, 加大科技投入, 形成以国家氢能安全实验室为主体, 社会科技力量积极参与的研究体制; 二是加快修订完善 车用氢能安全标准体系; 三是构建 $70 \mathrm{MPa}$ 涉氢装备制造体系。

关键词: 氢能; 燃料电池汽车; 安全技术; 标准体系

中图分类号：TK91 文献标识码：A

\section{Technologies for the Safe Use of Hydrogen and Construction of the Safety Standards System}

\author{
Cao Xianghong, Wei Zhiqiang
}

(China Petrochemical Corporation, Beijing 100728, China)

\begin{abstract}
The industry of hydrogen energy for fuel cell electric vehicles (FCEVs) is in a rapid start-up stage in China. Understanding of the danger of hydrogen and safe use of the hydrogen energy are the basis for the healthy development of the FCEV industry. In this study, we analyze the physical and chemical properties of hydrogen and the compatibility issues for hydrogen and materials and then propose three basic principles for the safe use of hydrogen. Subsequently, the research outputs and technical measures for the safe use of high-pressure hydrogen energy in Japan are thoroughly introduced and some suggestions are presented for the safe use of hydrogen in accordance with the Chinese situation. First, China should conduct overall planning and design, increase investment in science and technology, and form a research system that takes the National Hydrogen Safety Laboratory as the main body and has active participation from social science and technology forces. Moreover, it should perfect its hydrogen safety standards system for vehicles and build a $70 \mathrm{MPa}$ hydrogen-related equipment manufacturing system.
\end{abstract}

Keywords: hydrogen energy; fuel cell electric vehicle; safety technology; standards system

收稿日期 : 2020-01-12; 修回日期 : 2020-06-30

通讯作者 : 曹湘洪, 中国石油化工集团有限公司正高级工程师, 中国工程院院士, 主要从事石油化工与新能源研究工作;

E-mail: weizhq@sinopec.com

本刊网址：www.engineering.org.cn/ch/journal/sscae 


\section{一、前言}

我国燃料电池汽车 (FCEV) 产业刚进入市场 导入期就呈现了快速发展的态势, 截止 2019 年年 底, 累计销售燃料电池汽车 6184 辆, 建成加氢站 51 座, 形成了涵盖氢生产、氢储运、加氢站、燃 料电池、 $\mathrm{FCEV}$ 及关键设备和部件的产业链雏形, 20 多个省市发布了指导和支持 FCEV 产业发展的规 划、方案和意见, 预计到 2030 年我国 FCEV 保有 量将达 200 万辆、加氢站数量达 1000 余座。

氢气是易燃易爆气体，利用过程的安全措施一 旦失当, 容易发生着火爆炸事故, 造成人员伤亡和 财产损失 [1], 但目前对氢气的危险性解读存在一 些误区。2019 年, 美国、韩国、挪威分别在氢运 输、储存、加注过程发生了氢安全事故, 导致当地 宣布暂停加氢站运营, 引发了业界对 FCEV 产业健 康发展的担忧和对氢能利用安全技术研究的重视与 关注。氢能安全利用贯穿氢气的生产、储运、加注、 FCEV 利用等环节, 是 FCEV 产业健康发展的首要 保障。

相对于 FCEV、加氢站及相关产业的快速发 展, 我国对氢能利用安全技术的系统性研究相对贵 乏, 落后于产业发展的现实需求, 尚不具备支撑产 业健康快速发展的能力。一是我国氢能安全技术研 究基础薄弱, 氢能安全技术研究主要集中在氢燃料 电池安全、氢行为、涉氢设备的材料相容性等基 础领域 [2 5], 研究力量分散、深度不足, 涉氢设 备、材料和部件的安全可靠性测试方法和检测认证 手段缺乏, 燃料电池安全、整车安全、储氢罐安全 研究不能包括实际应用过程的所有事故场景, 加氢 站安全技术研究接近空白。二是我国已建立的车用 氢能安全法规标准缺少科学性和完整性。目前我国 FCEV 相关的标准制定由国家标准化委员会下设的 若干标准技术委员会负责，主要涵盖整车标准、燃 料系统、基础设施、通用基础等方面。这些标准以 借鉴、参考、翻译国外标准为主, 缺乏足够的实验 数据和必要的安全技术研究支撑。如《加氢站技术 规范》（GB50516-2010）对加氢站与民用建筑的 防火距离设置, 我国规定为 $20 \sim 35 \mathrm{~m}$, 国外采用风 险评估后确定, 日本控制在 $8 \mathrm{~m}$ 以上。简单从严选 择, 借鉴国外标准使标准的科学性、合理性不足,
不利于我国 FCEV 产业的健康发展。三是我国不具 备国外普遍使用的 FCEV 供氢系统装备的产业化能 力, 与之相关的安全技术研究处于空白状态。国外 供氢系统压力普遍是 $70 \mathrm{MPa}$, 由于技术和制造能 力限制, 我国 FCEV 用氢压力为 $35 \mathrm{MPa}$ 。 $35 \mathrm{MPa}$ 供氢压力极大降低了 FCEV 的行驶里程, 增加了氢 气的储存运输成本, 未来采用 $70 \mathrm{MPa}$ 系统是必然 趋势, 必须有可靠的检验测试标准和方法做保障。 在制定标准时虽然可以借鉴国外的研究成果, 但我 国应该具备自主进行 $70 \mathrm{MPa}$ 和 $90 \mathrm{MPa}$ 储氢瓶, 加 氢站建设使用阀门、管件、仪表、加氢枪等的安全 可靠性及使用寿命测试认证的能力。

日本是世界上 FCEV 技术开发与市场推广领先 的国家, 开展了系统的安全技术研究, 建立了设施 完备的车用氢能安全研究测试机构, 形成了系统 全面的临氢承压储氢瓶、阀门、仪表、管件等的 安全检测检验方法和标准体系, 其经验具有一定 的参考和借鉴价值。为此, 本文首先指出应科学 认识氢气的危险性, 并根据氢气的物理化学性质, 合理制定用氢安全对策; 然后以较大篇幅详细介 绍了日本的氢能利用安全技术研究情况及启示; 最后提出了加强我国氢能利用安全技术研究与标 准体系建设的建议, 以支撑我国 FCEV 产业的健 康发展。

\section{二、科学认识氢气危险性, 合理制定用氢安 全对策}

\section{（一）氢气的物理化学性质}

氢是自然界广泛存在的元素, 煤炭、石油、天 然气、动物、植物乃至人体都含有氢元素。氢气 具有无色、无味、无毒、可燃易爆的特点, 密度 为 $0.0899 \mathrm{~kg} / \mathrm{Nm}^{3}$, 沸点为 $-252.8^{\circ} \mathrm{C}$, 常温下, 氢 气性质稳定 [6,7]。表 1 列出了汽油、天然气、氢 气的物理化学性质。与汽油和天然气相比, 氢气 具有三个特性。一是氢气爆炸浓度下限与燃烧浓度 下限差值远高于汽油和天然气。易燃易爆气体与空 气混合后遇明火引燃, 当其浓度即单位体积能量密 度达到引爆需要的能量时，才会发生爆炸，所以燃 烧与爆炸的浓度范围理论上是有差异的, 但是不少 易燃易爆气体的燃烧浓度范围限值与爆炸浓度范围 
限值差异不大，准确测定困难，如汽油和天然气的 燃烧浓度范围下限与爆炸浓度下限差值较小，汽油 为 $0.1 \mathrm{v} \%$, 天然气为 $1.0 \mathrm{v} \%$ 。为了强调其爆炸的 危险性，一些文献资料只介绍爆炸浓度范围，甚至 将燃烧浓度范围直接作为爆炸浓度范围。在分析 氢气的安全性时, 既要关注燃烧浓度范围, 也要 关注爆炸浓度范围 [7,8]。氢气的爆炸浓度范围是 $18.3 \mathrm{v} \% \sim 59.0 \mathrm{v} \%$ ，燃烧浓度范围是 $4.0 \mathrm{v} \% \sim 75.0 \mathrm{v} \%$, 两者之间是有明显差异的, 如果将氢气的燃烧浓度 范围（4.0 v\% 75.0 v\%）当作爆炸浓度范围，就放 大了氢气的易爆性。二是氢气燃烧时单位体积发热 量和单位体积爆炸能相对较低。氢气燃烧时单位体 积发热量仅为汽油的 $0.053 \%$, 单位体积的爆炸能 量为汽油的 $4.57 \%$ 。三是氢气的比重最低。当空气 的比重为 1 时, 汽油蒸气的比重在 3.4 4.0, 氢气仅 为 0.0695 , 汽油在空气中泄漏时会积聚在地面上, 氢气泄漏至空气中很容易向上扩散, 在受限空间内 会集聚在上部，如果受限空间的上部有良好的通风 措施, 氢气就不容易集聚。熟悉和了解氢气的三个 特性, 对制定氢能安全利用对策十分重要。

\section{（二）氢与材料的相容性问题}

氢与材料的相容性问题是高压氢气系统选择 金属材料时必须十分重视的问题，与储氢瓶、管 线、阀门、仪表、管件使用中的安全性密切相关。 氢气在达到一定温度和压力时, 会解离成直径很小 的氢原子向金属材料中渗透，进入材料的氢原子又 会在材料内部转化为氢分子, 还会和材料中的碳发
生反应造成脱碳并生成甲烷，从而在材料内部产生 很大的应力, 使材料的塑性和屈服强度下降而造成 材料发生裂纹与断裂。前人对高温高压临氢环境 下如何防止氢脆与金属材料的选择开展了大量研究 工作 $[9,10]$ 。图 1 显示了温度范围在 $150 \sim 820^{\circ} \mathrm{C}$ 临 氢作业用钢防止脱碳和微裂的操作极限, 可以作为 目前 FCEV 供氢系统金属材料选择的参考，但是 FCEV 供氢系统压力高, 温度不高, 部分环节是低 温环境, 使用的氢气纯度高, 如何选择材料防止 氢脆, 提高氢气与材料的相容性应进行必要的研 究, 而且 FCEV 供氢系统要在升压降压反复循环 条件下长期运行，材料选择时还必须十分关注材料 的抗疲劳性能。

\section{（三）氢能利用的安全对策}

氢气和天然气均为易燃易爆气体，对比物理化 学性质, 氢气的危险性不高于天然气。天然气已经 进入千家万户成为日常使用的清洁燃气，像管理天 然气一样管理氢气, 落实安全措施, 氢能是可以安 全利用的。鉴于氢气的物理化学性质和天然气安全 使用的经验, 氢气的安全利用应遵守三个基本原则:

一是不泄漏, 即防止氢气尤其是压缩氢气系统的氢 气泄漏。要确保储氢瓶、阀门、安全阀、管件、接 头及连接件、仪表、垫圈的可靠性，选用的金属材 料与氢要有良好的相容性。二是早发现, 即氢气泄 漏后能及早发现。要在容易发生氢气泄漏的部位设 置高灵敏度的氢气浓度自动检测仪表及报警装置, 一旦发生泄漏能及时报警处理。三是不积累，即防

表 1 汽油、天然气、氢气的物理化学性质

\begin{tabular}{lccc}
\hline 物性 & 汽油 & 天然气 & 氢气 \\
\hline 分子量 & $\sim 107.0$ & 16.043 & 2.016 \\
颜色 & 有 & 无 & 无 \\
气味 & 有 & 无 & 无 \\
最小点火能量 $/ \mathrm{MJ}$ & 0.24 & 0.29 & 0.019 \\
燃烧浓度范围 $/ \mathrm{v} \%$ & $1.0 \sim 7.6$ & $5.3 \sim 15.0$ & $4.0 \sim 75.0$ \\
爆炸浓度范围 $/ \mathrm{v} \%$ & $1.1 \sim 3.3$ & $6.3 \sim 13.5$ & $18.3 \sim 59.0$ \\
扩散系数 / $\left(\mathrm{m}^{2} \cdot \mathrm{s}^{-1}\right)$ & $5 \times 10^{-6}$ & $1.6 \times 10^{-5}$ & $6.1 \times 10^{-5}$ \\
比重 $($ 空气 $=1)$ & $3.4 \sim 4.0$ & 0.55 & 0.0695 \\
自燃温度 $/{ }^{\circ} \mathrm{C}$ & 228 & 540 & 527 \\
单位体积发热量 / $\left(\mathrm{MJ} \cdot \mathrm{Nm}^{-3}\right)$ & 242.7 & 55.5 & 12.8 \\
单位体积爆炸能 $/\left(\mathrm{Gtnt} \cdot \mathrm{Nm}^{-3}\right)$ & 44.22 & 7.03 & 2.02 \\
\hline
\end{tabular}


止氢气泄漏后的积聚。受限空间如加氢站储氢瓶的 储存间和氢气压缩机间要具备良好的通风性能, 易 发生氢气泄漏的部位要设置与氢气检测报警联动的 防爆强制通风设备, 氢气泄漏时要能够迅速启动强 制通风设备, 使氢气尽快向空中扩散。

\section{三、日本氢能安全技术研究及启示}

\section{（一）日本支持氢能发展战略的安全技术研究}

日本在建设氢能社会和发展 FCEV、家用燃料 电池等领域处于世界领先地位。2014 年日本发布了
建设氢能社会的路线图，2017 年发布了氢能发展战 略, 明确了 2020 年和 2030 年的战略发展目标（见 表 2), 成为世界上第一个提出建设氢能社会的国 家。在政府的支持下，日本企业、科研机构和高校 从 20 世纪 80 年代起就围绕氢能利用的基础理论、 应用技术、仪器仪表装备制造等开展了系统研究， 其中, 氢能利用中的安全技术是最为重要的内容之 一。进行氢能利用安全技术研究后, 日本认为其《高 压气体保安法》可作为制定安全利用氢能标准规范 的依据。

由政府与汽车企业各提供 $50 \%$ 资金建设和运

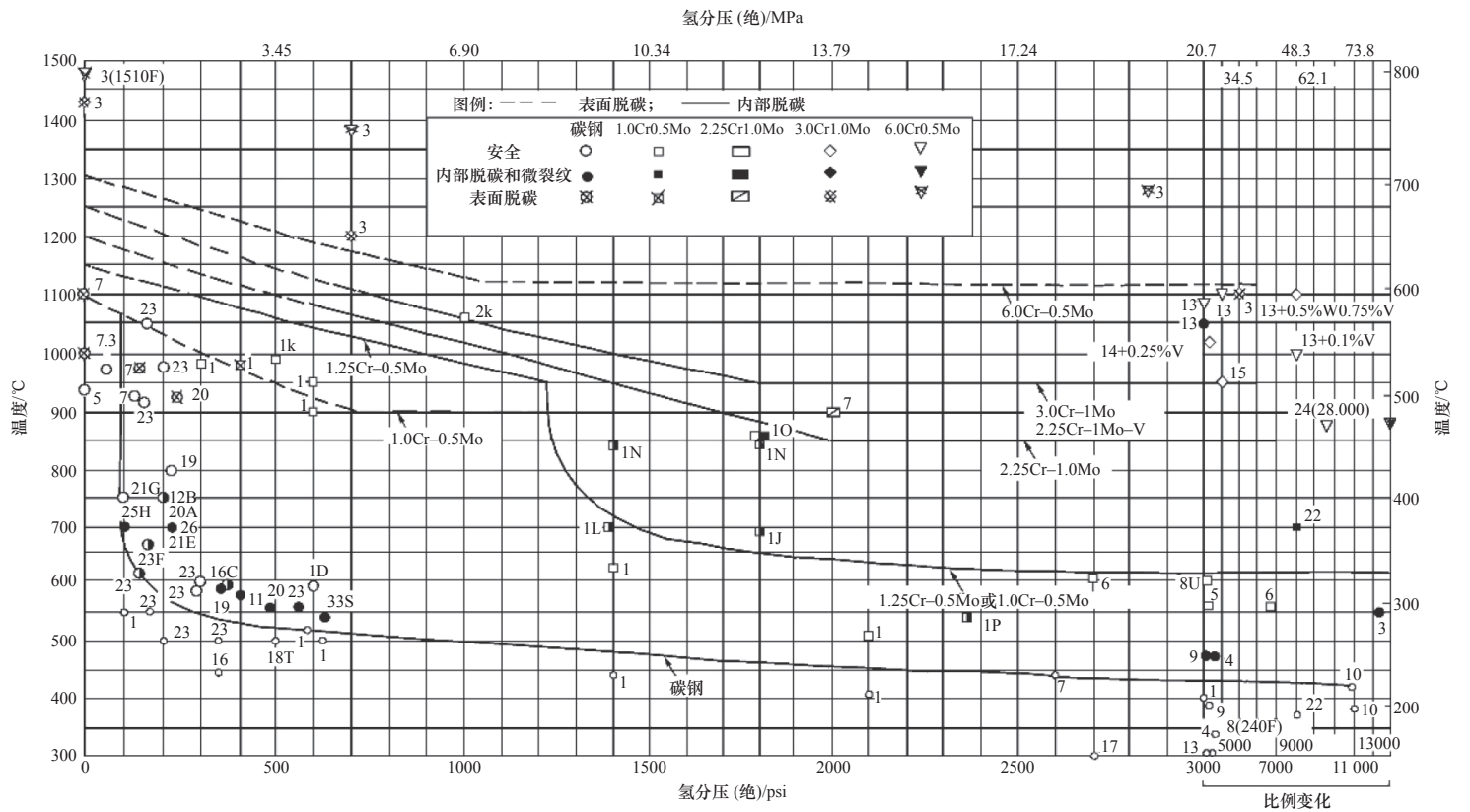

图 1 临氢作业用钢防止脱碳和微裂的操作极限

表 2 日本氢能发展战略目标

\begin{tabular}{|c|c|c|c|c|c|}
\hline 名称 & 单位 & 现状 & 2020 年 & 2030 年 & 战略目标 \\
\hline 氢源 & - & $\begin{array}{l}\text { 化石能源制氢（副 } \\
\text { 产氢、天然气制氢） }\end{array}$ & $\begin{array}{l}\text { 化石能源制氢（副产 } \\
\text { 氢、天然气制氢） }\end{array}$ & 可再生能源制氢 & $\begin{array}{c}\text { 零碳排放制氢 } \\
\text { (碳捕获与封存、可再生能源) }\end{array}$ \\
\hline 氢气消费量 & $\times 10^{4} / \mathrm{a}$ & 0.02 & 0.4 & 30 & 1000 \\
\hline 氢气价格 & $\mathrm{USD} / \mathrm{kg}$ & 10 & - & 3 & 2 \\
\hline 燃氢电站 & - & 研发 & - & $\begin{array}{c}1 \times 10^{6} \mathrm{~kW} \\
17 \text { 日元 } /(\mathrm{kW} \cdot \mathrm{h}) \\
(1 \text { 元 } / \mathrm{kW} \cdot \mathrm{h})\end{array}$ & $\begin{array}{c}3 \times 10^{7} \mathrm{~kW} \\
12 \text { 日元 } /(\mathrm{kW} \cdot \mathrm{h}) \\
(0.7 \text { 元 } / \mathrm{kW} \cdot \mathrm{h})\end{array}$ \\
\hline 加氢站 & 座 & 100 & 160 & 900 & 取代加油站 \\
\hline 氢燃料乘用车 & 万辆 & 0.2 & 4 & 80 & 取代汽油车 \\
\hline 氢燃料巴士 & 辆 & 2 & 100 & 1200 & 取代汽油车 \\
\hline 氢燃料叉车 & 辆 & 40 & 500 & 10000 & 取代汽油车 \\
\hline 燃料电池发电 & 万台 & 22 & - & 530 & 取代传统居民供能系统 \\
\hline
\end{tabular}


行的日本自动车研究所是日本开展车用氢能安全研 究的重要机构, 建有世界上第一座可以进行 FCEV、 电动汽车 $(\mathrm{EV})$ 、内燃机汽车火灾爆炸评价测试的 大型试验仓, 如图 2 所示, 还建有高压氢气试验设 备、液压试验设备、液化氢试验设备等。开展了容 量为 $260 \mathrm{~L}$ 的 $70 \mathrm{MPa}$ 储氢瓶破坏性试验、FCEV 整 车火烧试验、氢气泄漏火灾爆炸试验、高压氢系统 设备破坏性测试、容器阀门等的循环寿命和耐久性 试验、高压氢安全加注程序研究, 以及 FCEV、电 动汽车和汽油车安全性对比研究等, 为支撑日本车 用氢能安全利用做出了重要贡献。

\section{（二）高压储氢瓶设计制造与安全可靠性检测}

日本 FCEV 采用 $70 \mathrm{MPa}$ 的高压氢气, 加氢站 氢气压缩机出口压力及储氢瓶最高压力达 $90 \mathrm{MPa}$, 储氢瓶制造的可靠性及安全性能测试十分重要。 $70 \mathrm{MPa} 、 90 \mathrm{MPa}$ 储氢瓶一般采用 3 层结构, 表层 采用玻璃纤维复合材料, 中间层采用碳纤维复合 材料, III 型瓶内层采用铝合金内胆, IV 型瓶内层 采用塑料内胆。储氢瓶口与出口阀的结合部位通 过特殊的结构设计确保阀门在使用压力下不会像 炮弹出膛一样被冲出, 瓶身部位玻璃纤维及碳纤 维复合材料采用特殊的缠绕方法确保储氢瓶的强 度达到长期使用要求。储氢瓶设计及制造技术的 可靠性要通过水压爆破试验、枪击试验和火烧试 验测试等检测, 还要通过汽车碰撞试验测试储氢 瓶的安全性。

日本 $70 \mathrm{MPa}$ 储氢瓶水压爆破试验压力为 $200 \mathrm{MPa}, 90 \mathrm{MPa}$ 储氢瓶水压爆破试验压力为

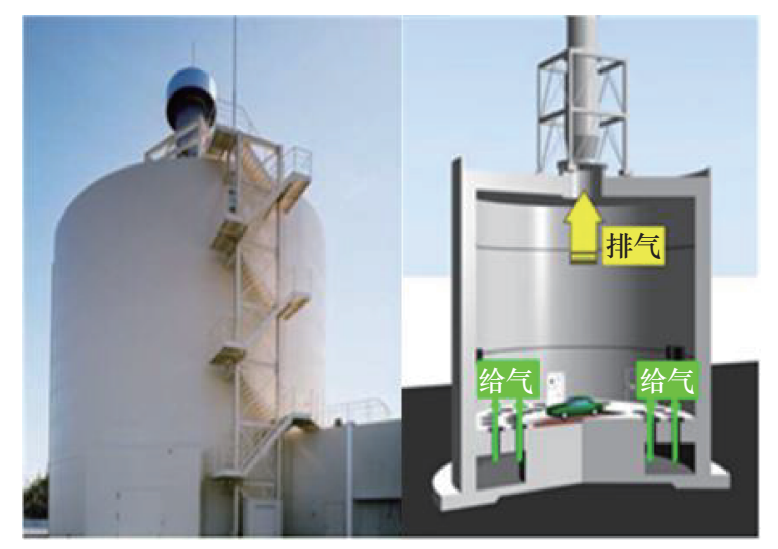

图 2 日本自动车研究所的防爆火灾试验仓
$300 \mathrm{MPa}$ ，高于 ISO/TS15869、ISO11439 等关于高 压储氢瓶的破坏性试验压力为操作压力 2.25 倍合 格值的规定。用 $7.62 \mathrm{~mm}$ 穿甲弹正面枪击储氢瓶, 子弹卡在储氢瓶壳层内, 不能击穿瓶体。当暴露在 火灾中的储氢瓶内温度达到 $105{ }^{\circ} \mathrm{C}$ 后, 储氢瓶熔断 安全阀会迅速打开, 朝预先设定的熔断阀出口方 向快速泄放, $70 \mathrm{MPa}$ 容积为 $60 \mathrm{~L}$ 的储氢瓶大约需 要 $1 \mathrm{~min}$ 排空氢气, 瓶内气体喷射的氢气迅速燃烧 不发生爆炸, 火焰长度最长可达 $10 \mathrm{~m}$ 。丰田 Mirai FCEV 被 $80 \mathrm{~km} / \mathrm{h}$ 车辆追尾碰撞造成车身损毁时储 氢瓶完好无损。

\section{（三）高压氢系统设备材料安全性能评价测试}

高压氢气系统使用的金属材料必须经过材料安 全性能测试 (见图 3)。加氢枪使用的软管在高压 下要能反复经受低温 $\left(-40^{\circ} \mathrm{C}\right)$ 到高温 $\left(85^{\circ} \mathrm{C}\right)$ 的 循环测试。截止阀、流量调节阀、紧急切断阀、安 全阀、高压气瓶熔断阀等阀门和管件垫圈都要在高 压氢环境下进行长期使用性能测试。加氢枪加氢时 充注的氢气温度高于 $85^{\circ} \mathrm{C}$ 时, 必须立即停止加氢 的温度传感器和光纤要进行稳定性和可靠性测试。 加氢使用的流量计要经过高压氢环境下计量准确 性测试。氢气泄漏或着火后自动检测报警的传感 器要进行灵敏性准确可靠性测试。

为做好上述高压氢气系统的设备仪表材料安全 性能的评价测试，福冈市政府投资建设了福冈氢能 测试研究中心, 该中心有齐全且专业的测试实验室, 其中包括抗爆试验仓、高压氢用阀门耐久性测试、 加氢高压软管低温循环测试、 $\mathrm{O}$ 型圈疲劳测试、加 氢站储氢瓶破坏性测试等测试实验室, 他们既研究 测试试验的方法, 还接受设备及材料制造商和用户 的委托开展安全性能测试，合格后方可投放市场。

\section{（四）加氢站安全技术措施}

日本的加氢站一般建在交通便利、方便用户 的地段, 或在人口稠密处或在交通要道上。日本允 许在加油站内建设加氢站, 即油氢混合站。还允许 加氢站内建设集装箱式天然气或以丙烷为原料的制 氢装置, 即在线制氢加氢站。加氢站内既有大容量 高压储氢瓶, 也有高压压缩机、氢气接卸设施。加 氢站与周边建筑物的安全距离只要求遵守《高压气 


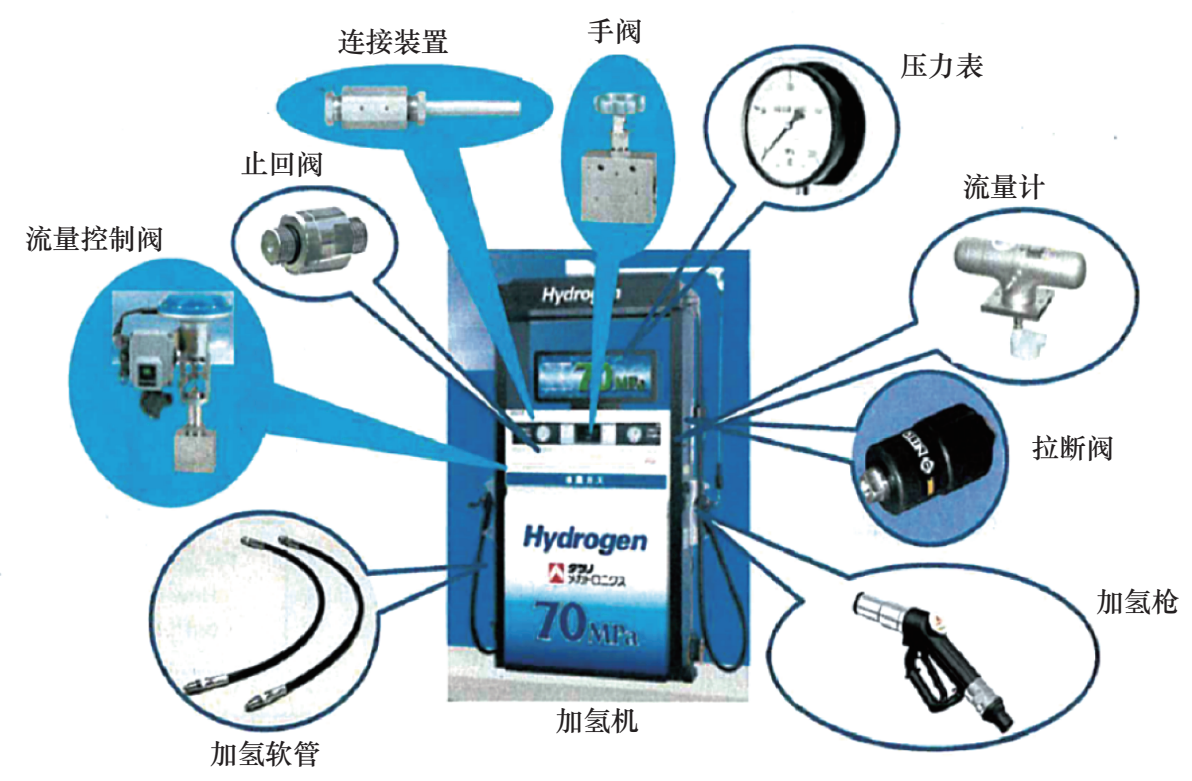

图 3 需要进行可靠性测试的加氢系统关键组件

体安全法》的规定, 和居民住宅及各类公共设施的 距离不小于 $8 \mathrm{~m}$, 加氢站和民宅、公共设施设置厚 $10 \mathrm{~cm}$ 的隔离墙。

为确保加氢站的安全, 采取的安全技术措施 主要有: 在氢气容易泄漏的部位都设有高灵敏度 氢气泄漏检测器, 氢气体积浓度高于 $1 \%$ 时及时报 警, 设有多台火焰检测器, 能及时发现站内氢气 着火并进行报警。高压储氢间、氢压缩机间等建 筑物要考虑氢气泄漏后不积聚, 采用既防雨水又 易排气的屋顶设计，室外加氢机顶棚设计要有利 于氢气向高空扩散。

\section{（五）FCEV 安全设计与安全性能测试}

丰田 Mirai 的 2 个储氢瓶用底盘和车体内部空 间实现隔离（见图 4), SORA 公共汽车的 10 个储 氢瓶设置在车顶, 靠顶板实现氢气和汽车内部空间 的隔离, 防止氢气泄漏到车厢内（见图 5)。车身安 装碰撞传感器, 检测到碰撞时会自动关闭储氢瓶出 口阀门。Mirai 在车身设置 2 台氢气探测器, SORA 设置 4 台氢气探测器, 检测到氢气泄漏时也会立刻 关闭储氢瓶出口阀门, 确保氢气泄漏后可检测、可 及时终止泄漏。车身采用流线型设计, 利于氢气扩 散, 确保氢气泄漏后不积聚。

为评价氢气泄漏对 FCEV 安全性能的影响, 开 展了氢气扩散模拟试验、氢气着火时的燃烧动态试

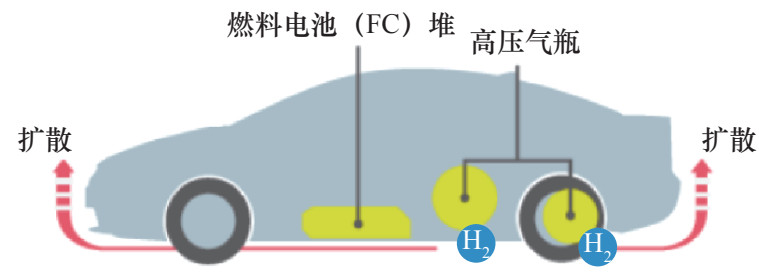

图 4 丰田 Mirai 氢燃料关联零部件设置示意图

验、管路等有微小泄漏点火试验、氢气泄漏后滞留 在汽车某部位点火试验、假设氢气充满在车厢点火 试验、通过安全阀放出的氢气着火试验、车辆着火 试验等。氢气泄漏后滞留在汽车某部位点火试验 以 $131 \mathrm{~L} / \mathrm{min}$ 向汽车前后轴中间部位释放氢气, 约 $100 \mathrm{~s}$ 后氢浓度达到 $23.8 \%$, 用电火花打火发生燃爆, 前挡风玻璃附近和车体下部有高温部位，燃爆压没 有导致车体变形, 热辐射是地面太阳光热量的 $1 / 10$ 以下, 没有观测到冲击压强, 声音压强远低于伤害 耳膜的等级。在氢气充满车厢点火试验中, 氢浓度 在 $12 \%$ 以下, 电火花打火, 瞬间氢气着火, 但不 足以点燃车厢内餐巾纸 (燃烧发热量小); 能使车 玻璃破碎的爆炸冲击波需要氢浓度达到 $40 \%$ 以上。 在破坏 $\mathrm{FCEV}$ 储氢瓶和汽油车油箱漏油后的车辆着 火试验中, FCEV 的储氢瓶氢气泄放并向上燃烧, 约 $1 \mathrm{~min}$ 后熄火。汽油油箱向下漏油, 持续燃烧, 导致轮胎和车体着火, 车辆烧毁。电动汽车因电池 温度失控、隔膜破裂导致火灾无法扑灭，着火时间 


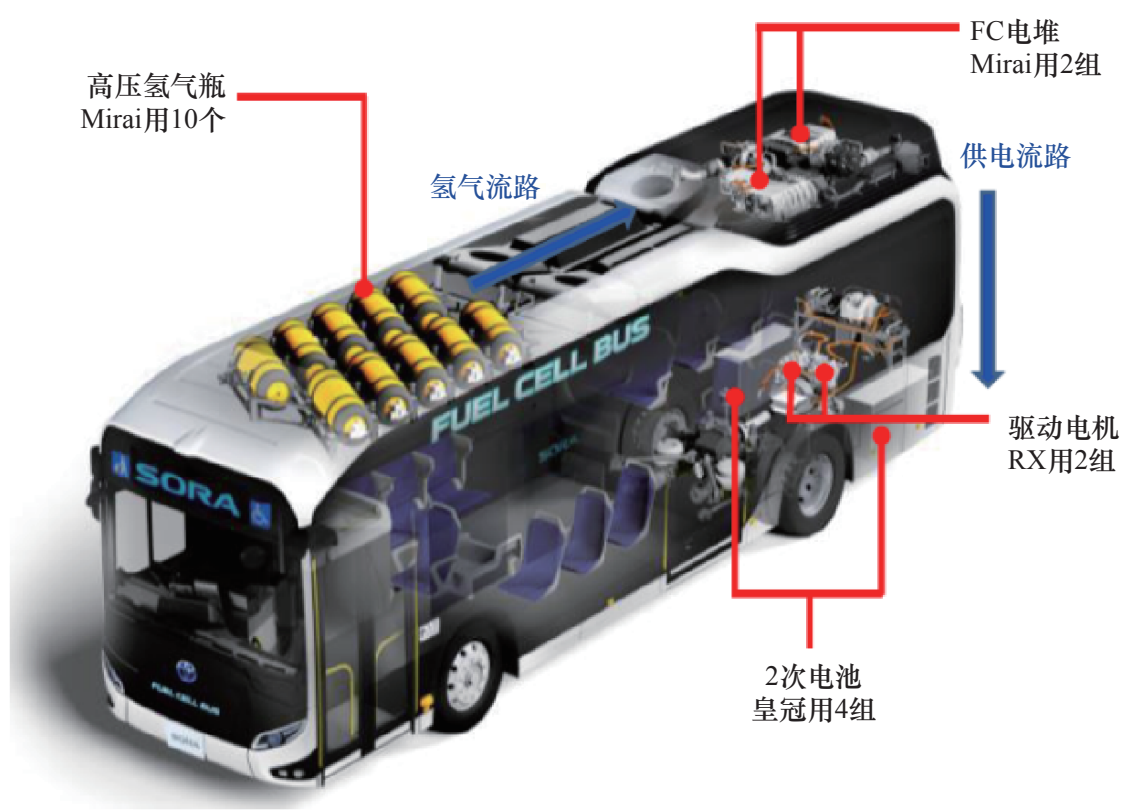

图 5 丰田 SORA 氢燃料关联零部件设置示意图

约 $1 \mathrm{~h}$, 车辆烧毁。试验结果表明: FCEV 的安全性 与燃油车、天然气车相当, 优于电动汽车。

\section{四、加强我国车用氢能安全技术研究与标准 体系建设的建议}

（一）总体规划设计, 加大科技投入, 形成以国家 氢能安全重点实验室为主体, 社会科技力量 积极参与的研究体制

氢能安全技术是实现 FCEV 发展目标的重要支 撑性公用技术, 应由国家安全生产主管部门总体规 划设计并筹建氢能安全国家重点实验室。要借鉴国 外经验, 明确氢能安全技术必须覆盖的研究项目、 必须建设的实验设施和装备, 建设投资和日常研究 经费应列入中央财政, 确保适时投入。氢能安全国 家重点实验室的研究工作应由国家安全生产主管部 门管理, 氢能安全利用的标准规范制定应由国家实 验室负责。

氢能安全利用技术研究还需要发挥地方政府和 企业的积极性, 允许有条件的省市和企业建设氢能 检测与研究机构, 机构应由国家安全生产主管部门 审定批准, 测试仪器设备设施和技术力量应满足国 家标准规范的要求, 可有偿接受氢能系统设备、材 料、阀门、管件、仪器、仪表、加氢枪的检测鉴定
认证。逐步形成以氢能安全国家重点实验室为主体, 社会科技力量积极参与的研究体制。

\section{（二）加快修订完善车用氢能安全标准体系}

建立先进完整的车用氢能安全标准体系, 是支 撑 FCEV 及相关产业科学、健康发展的迫切需要。 车用氢能的开发利用涉及制氢、氢气压缩或液化储 存、运输、加注、燃料电池、FCEV 等诸多环节, 既要确保安全又要有利于 FCEV 的发展。日本在车 用氢能领域建立了先进、完整的标准体系, 如针对 FCEV, 高压氢系统 (包括高压储氢瓶和容器主阀) 适用《高压气体保安法》, 其余车辆系统适用《道 路运送车辆法》。针对加氢站遵循的法律标准、规 范主要有: 《高压气体保安法》《消防法》《建筑基 准法》《加氢站安全检查标准》等。目前我国发展 FCEV 的热度不比日本低, 但与 FCEV 安全有关的 国家强制性标准缺少完整性, 有些标准也缺少先进 性。如《加氢站技术规范》, 是十年前借鉴国外标 准组织相关规范, 经国内有关专家讨论后制定的, 与国外加氢站现行的技术标准相比, 先进性存在不 足。近十多年来, 国际氢能利用快速进步, 安全标 准也在实践中不断修改完善, 我们需要在系统研究 安全技术和借鉴国外先进标准的基础上不断修改完 善我国车用氢能安全标准体系。 


\section{（三）重视构建 $70 \mathrm{MPa}$ 涉氢装备制造体系}

构建 $70 \mathrm{MPa}$ 涉氢装备制造体系, 是发展 FCEV 的一项重要基础性工作。我国 $70 \mathrm{MPa}$ 以上压缩氢 系统装备制造能力与日本、欧美存在较大差距，储 氢瓶、FCEV 及加氢站涉及的关键设备、仪表、阀 门、加氢枪、压缩机等均不具备产业化能力, 完 全依靠进口。不脱除此瓶颈约束, FCEV 成为我国 经济未来的增长点是不可能实现的。 $70 \mathrm{MPa}$ 涉氢 系统的装备制造与我国新材料研发与生产、高端装 备开发与制造能力密切相关, 是装备制造业迈向 高质量发展的重要标志。应加大科研投入，开展 $70 \mathrm{MPa} 、 90 \mathrm{MPa}$ 储氢瓶和氢气压缩机及关键零部 件如阀门、仪表、高灵敏氢气检测传感器、氢气 火焰传感器的制造能力攻关, 尽快实现 $70 \mathrm{MPa}$ 涉 氢装备由中国制造。

\section{参考文献}

[1] 梁慧. 日本氢能源技术发展战略及启示 [J]. 国际石油经济, 2016, 24(8): 87-95.

Liang H. The development strategy of Japan's hydrogen energy technology and its enlightenment [J]. International Petroleum Economics, 2016, 24(8): 87-95.

[2] 郑津洋, 刘自亮, 花争立, 等. 氢安全研究现状及面临的挑战 [J]. 安全与环境学报, 2020, 20(1): 106-115.

Zheng J Y, Liu Z L, Hua Z L, et al. Research status-in-situ and key challenges in hydrogen safety [J]. Journal of Safety and Environment,
2020, 20(1): 106-115.

[3] 郭婷, 杨沄茫, 王金伟, 等. 燃料电池汽车氢电安全法规标准的 研究 [J]. 客车技术与研究, 2018, 4(1): 57-59.

Guo T, Yang Y P, Wang J W, et al. Research on regulations and standards about hydrogen and electricity safety for fuel cell vehicles [J]. Bus \& Coach Technology and Research, 2018, 4(1): $57-59$.

[4] 马秋玉, 赵子亮, 赵洪辉, 等. 燃料电池行业标准现状综述 [J]. 汽 车文摘, 2020, 1(1): 14-17.

Ma Q Y, Zhao Z L, Zhao H H, et al. Overview on the present situation of fuel cell industry standards [J]. Automotive Digest, 2020, 1(1): 14-17.

[5] 李志勇, 潘相敏, 罗义英, 等. 氢能基础设施安全距离确定方法 的比较与分析 [J]. 太阳能学报, 2013, 34(8): 1492-1498.

Li Z Y, Pan X M, Luo Y Y, et al. Comparison of determination approaches of safety distances for hydrogen infrastructure[J]. Acta Energiae Solaris Sinica, 2013, 34(8): 1492-1498.

[6] Hord J. Is hydrogen a safe fuel? [J]. International Journal of Hydrogen Energy, 1978, 3(2): 157-176.

[7] Rigas F, Amyotte P. Hydrogen Safety [M]. Florida: CRC Press, 2018 .

[8] Matsui H. 氢气爆炸特性研究 [J]. 中国安全生产科学技术, 2005, 1(6): 3-9.

Matsui H. Characteristics of hydrogen explosions [J]. Journal of Safety Science and Technology, 2005, 1(6): 3-9.

[9] Ibrahim R A. Corrosion and hydrogen embrittlement [M]. Manhattan: John Wiley \& Sons Ltd., 2017.

[10] American Petroleum Institute. API RP 941-2016 steels for hydrogen service at elevated temperatures and pressures in petroleum refineries and petrochemical plants [S]. Washington DC: API Publishing Services, 2016: 1-56. 